\title{
An effective removal of methylene blue dye using polyacrylonitrile yarn waste/graphene oxide nanofibrous composite
}

\author{
S. Swaminathan - A. Muthumanickkam • \\ N. M. Imayathamizhan
}

Received: 8 May 2014/Revised: 23 September 2014/ Accepted: 10 November 2014/Published online: 2 December 2014

(C) Islamic Azad University (IAU) 2014

\begin{abstract}
An electrospun nanofibrous composite mat was prepared from polyacrylonitrile yarn waste and graphene oxide. The physical and chemical properties of the nanofibrous composites were characterized using attenuated total reflections Fourier transform infrared, scanning electron microscopy, X-ray diffractometer, and TGA studies. The mean fiber diameters of the pristine polyacrylonitrile yarn waste nanofiber, polyacrylonitrile yarn waste/0.5 wt\% graphene oxide, polyacrylonitrile yarn waste/1.0 wt\% graphene oxide, and polyacrylonitrile yarn waste $/ 1.5 \mathrm{wt} \%$ graphene oxide nanofibrous composites were in the range of 41-50, 31-40, 31-40, and $31-40 \mathrm{~nm}$, respectively. The mean pore sizes of the polyacrylonitrile yarn waste nanofiber, polyacrylonitrile yarn waste/0.5 wt\% graphene oxide, polyacrylonitrile yarn waste/1.0 wt\% graphene oxide, and polyacrylonitrile yarn waste/1.5 wt\% graphene oxide nanofibrous composites were $0.5541,0.4533,0.4229$, and $0.4168 \mu \mathrm{m}$, respectively. The maximum dye removal efficiency was attained in the polyacrylonitrile yarn waste/1.5 wt $\%$ graphene oxide composite at basic $\mathrm{pH}$.
\end{abstract}

Keywords Polyacrylonitrile yarn waste - Graphene oxide - Scanning electron microscopy · Methylene blue . Capillary flow meter

S. Swaminathan $\cdot$ A. Muthumanickkam

N. M. Imayathamizhan $(\bowtie)$

Department of Textile Technology, Anna University, Chennai 600 025, India

e-mail: nmimayathamizhan@gmail.com

\section{Introduction}

Wastewater management is one of the global environmental challenges and the pollution of water resources by various pollutants also currently a major environmental issue as it would lead to a loss of biodiversity. The water system is an important ecosystem in the environment for the existence of biotic species. At present, it is very difficult to protect the water resources from domestic, agricultural, and industrial wastes. Particularly, dyes and pigments create severe problems to the environment. Synthetic organic dyes have been used in various industries such as textiles, tannery, food, and cosmetics, which lead to the pollution of the environment due to their high toxicity and non-biodegradability (Gupta and Suhas 2009). Among the different types of water pollutants, textile dyes are considered to be the most dangerous for the environment (Ayad and Abo El-Nasr 2010; Wong et al. 2003). It is estimated that annually 70,000 metric tons of commercial dyes are discharged into wastewater in the worldwide (Auta and Hameed 2011; Nassar et al. 2012). The release of textile effluents causes abnormal coloration of surface waters and the colored water system blocks the sunlight penetration, which is very essential for photosynthetic bacteria and aquatic plants. Methylene blue (MB) is the cationic dye, which is the most commonly used coloring matter for dyeing cotton, wool, and silk (Baybars et al. 2012).

Many methods such as chemical coagulation, photo degradation, membrane filtration, and adsorption have been studied conventionally for dye removal purpose (Gomes et al. 2005; Sivakumar and Palanisamy 2009). Though a number of techniques are available for dye removal from aqueous solutions, adsorption is one of the most efficient techniques used worldwide due to the high 
adsorption capacity, cost effectiveness, and simple handling process (Dubey et al. 2009; Christian Kemp et al. 2013; Linjun et al. 2013). Polyacrylonitrile (PAN) rapidly adsorbs the cationic dye molecules, due to the presence of the anionic groups in the polymer. Polyacrylonitrile is the most widely used polymer among all the polymers, because of its excellent spinnability and environmental stability (Pang and Gong 2008). Graphene oxide (GO) is prepared from natural graphite, which is a promising adsorbent material for the removal of cationic dye molecules from aqueous solutions (Bradder et al. 2011; Ramesha et al. 2011; Liu et al. 2012; Huang et al. 2003). The GO has a large surface area, and it also contains carboxyl, hydroxyl, carbonyl, and epoxide groups.

These functional groups of the graphene enhance the negative charge density on the layer in basic medium. Nanofibrous technology is an advanced technique and has rapidly grown over the last decade, which has been used for wastewater treatment (Teo and Ramakrishna 2006; Ohkawa et al. 2004). The non-woven material produced by the electrospinning technique (Buchkoa et al. 1999) has fine diameter (Saeed et al. 2008), large surface area, high porosity, high gas permeability, and small pore size (Qingqing et al. 2013). Moreover, the PAN yarn waste/GO nanofibrous composites have not yet been used for dye removal. Polyacrylonitrile yarn waste is an inexpensive wastage product in textile industry, which can be studied for the production of nanofibers via electrospinning. The nanofibrous composite adsorbents are an inexpensive and ready to use for removal of dyes. In this study, the PAN yarn waste/GO nanofibrous composite was produced by the electrospinning technique. The physical and chemical properties of the nanofibrous composites were studied using scanning electron microscopy (SEM), Fourier transform infrared (FTIR), Thermogravimetric analyzer (TGA), and X-ray diffractometer (XRD) techniques. The dye removal efficiency and adsorption capacity of the adsorbent was studied using the UV-Vis spectrometer.

\section{Materials and methods}

Graphene oxide (Sigma-Aldrich) was dispersed in dimethyl formamide (DMF; Sigma-Aldrich) and sonicated for $30 \mathrm{~min}$ at room temperature. Polyacrylonitrile yarn waste was dissolved with DMF at $60{ }^{\circ} \mathrm{C}$ and placed at sonicator for $30 \mathrm{~min}$, followed by the mixing of PAN yarn waste and GO solutions, under continuous stirring till a homogeneous solution obtained. The solution was taken into a $2-\mathrm{ml}$ syringe, which was fixed vertically in an electrospinning set up. A $15 \mathrm{kV}$ of anode and cathode was connected to the syringe needle and a metal collector drum, respectively. During the electrospinning, the distance between the needle and collecting drum was $15 \mathrm{~cm}$ and the flow rate of the spinning solution was $1 \mathrm{ml} / \mathrm{h}$.

Scanning electron microscopy analysis

The surface morphology of the PAN yarn waste/GO nanofibrous composite mat was studied by scanning electron microscopy. The average diameter of the nanofibers was measured from SEM image using image tool software (UTHSCSA).

Thermogravimetric analyzer (TGA)

The thermal stability of PAN yarn waste and PAN yarn waste/GO nanofibrous composite was analyzed using TGA (Perkin-Elmer). The temperature scans ranged from 30 to $800{ }^{\circ} \mathrm{C}$ at the rate of $20^{\circ} \mathrm{C} / \mathrm{min}$ under nitrogen gas atmosphere.

\section{Pore size distribution}

A capillary porometer (FPA-1500A, Porous Materials Inc., USA) was employed to measure the mean pore size and pore size distribution, where a wetting fluid GalwickTM (Porous Materials Inc.) with a surface tension of 15.9 dynes/cm was used.

\section{X-ray diffraction}

The PAN yarn waste nanofiber and PAN yarn waste/GO composite nanofibers were analyzed using an X-ray diffractometer, under $\mathrm{CuK} \alpha(\lambda=1.54)$ radiation at $40 \mathrm{kV} /$ $200 \mathrm{Ma}$. A scan was taken with $2 \theta$ values ranging from $10^{\circ}$ to $80^{\circ}$ at a rate of $5 \% \mathrm{~min}$. The crystallinity and crystal size of the samples were calculated, using an Eq. (1).

Crystal size $\left(A^{\circ}\right)=\frac{k \lambda}{\beta \cos \theta}$

where $\lambda$ is the wavelength of $\mathrm{X}$-ray $\left(A^{\circ}\right), k$ is the shape factor and value of $0.9, \beta$ is full width half maximum (FWHM), $\theta$ is Bragg angle.

Dye adsorption

One gram of MB dye (Sigma-Aldrich) was dissolved in $1,000 \mathrm{ml}$ of deionized water (stock solution). $10 \mathrm{ppm}$ of a working solution was prepared from the stock solution for 
all the experiments. $50 \mathrm{mg}$ of nanofibrous composite was placed in $100 \mathrm{ml}(10 \mathrm{ppm})$ of $\mathrm{MB}$ dye solution, under shaking condition at room temperature and optimized $\mathrm{pH} 8$. The adsorption rate of the nanofibrous composite was studied for 10, 20, 30, 40, and $50 \mathrm{ppm}$ dye concentration. The effect of $\mathrm{pH}$ on the dye adsorption rate of the nanofibrous composite was studied. The adsorption rate was measured using the UV-Vis spectrometer (Hitachi U-2800, Japan), with a scanning range of $400-700 \mathrm{~nm}$.

\section{Results and discussion}

\section{SEM analysis}

Figure 1a-d shows the SEM images of pristine PAN yarn waste nanofiber, $0.5,1.0$, and $1.5 \mathrm{wt} \%$ GO blended with PAN yarn waste nanofibrous composites. The figure shows that the fibers were randomly distributed in the nanofiber composite and the diameter of the nanofiber was calculated from the SEM image. Figure 2a-d shows the fiber diameter distribution in the range of $41-50,31-40,31-40$, and $31-40 \mathrm{~nm}$, respectively. From these results, it could be concluded that the diameter of the fibers diminished on increasing the percentage of GO in the polymer solution (Zhao et al. 2008) and the GO is attributed to the rough surface on the composite nanofibrous mat. The fiber arrangement and fiber diameter of the nanofibrous composite were evaluated from the SEM image, which is one of the factors to determine pore size and porosity of the fibrous composite. The pore size and porosity are playing a vital role for the removal of dye (Hasanzadeh and Moghadam 2013).

\section{FT-IR analysis}

The FT-IR analysis was carried out for the prepared PAN yarn waste/GO nanofibrous composites, to exam-
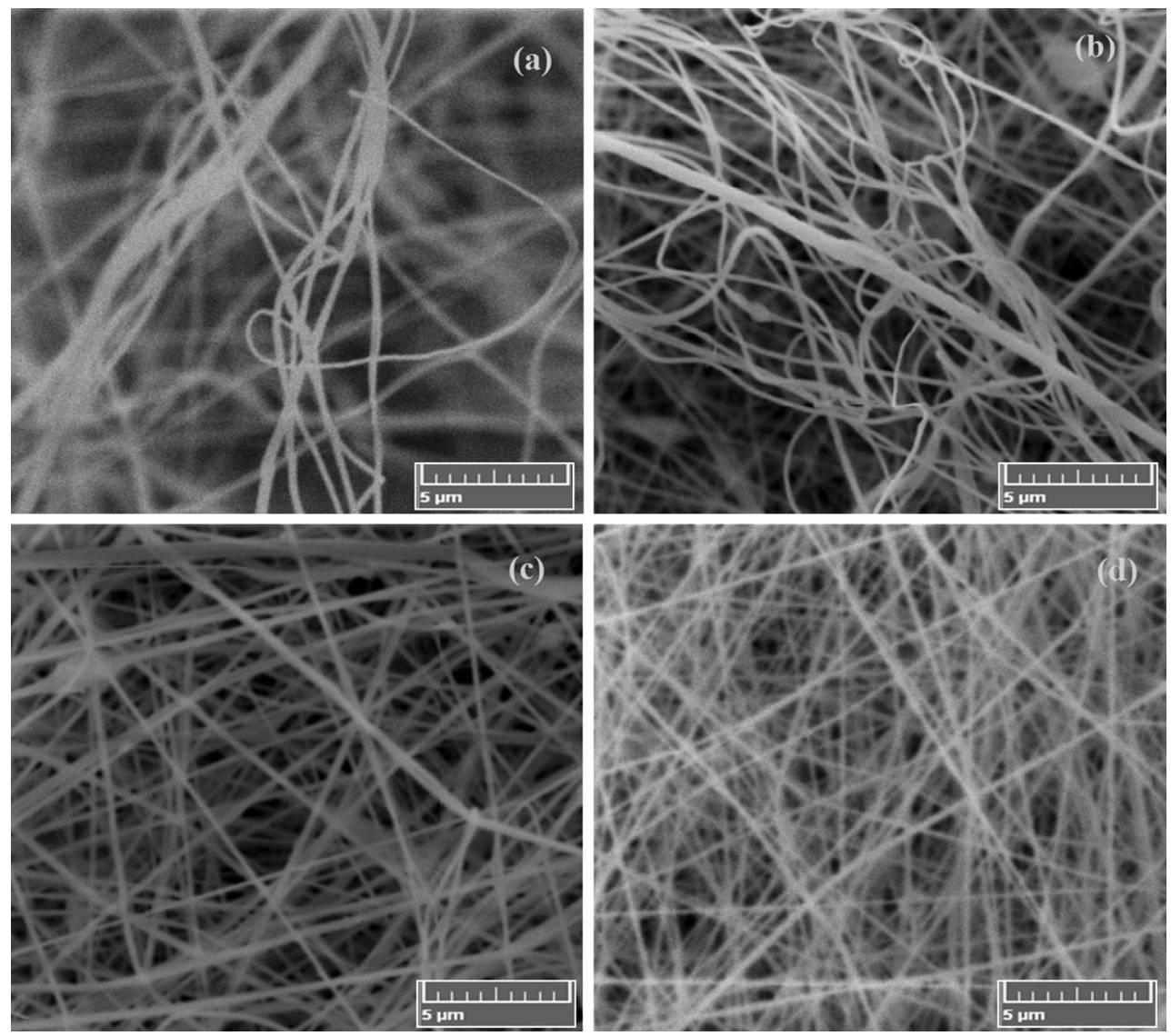

Fig. 1 SEM Images of a PAN, b PAN $+0.5 w t \%$ GO, c PAN $+1 w t \%$ GO, d PAN $+1.5 w t \%$ GO 


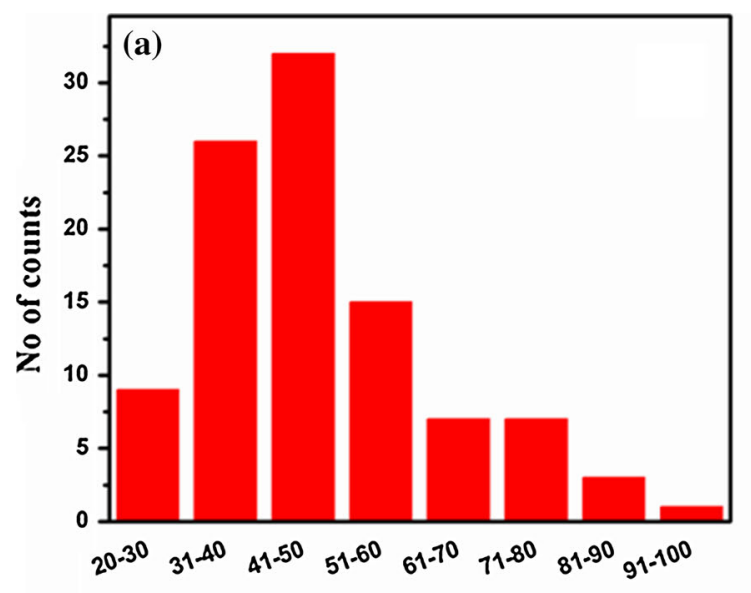

Fibre diameter $(\mathrm{nm})$

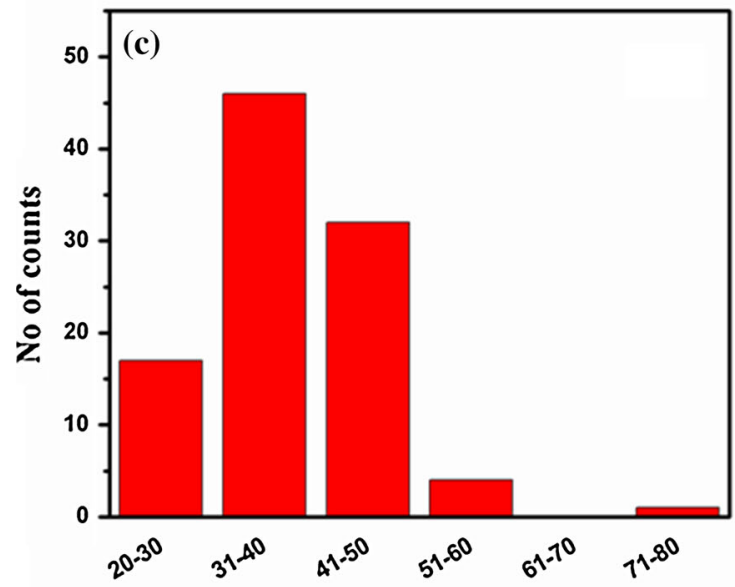

Fibre diameter (nm)

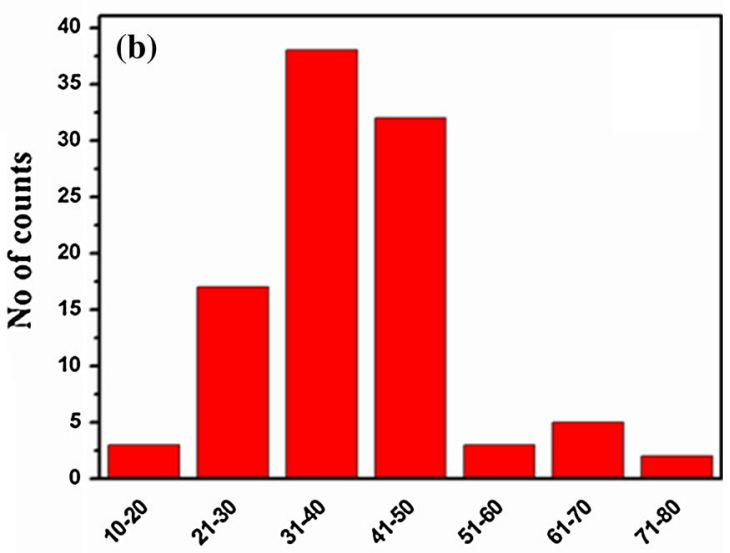

Fibre diameter (nm)

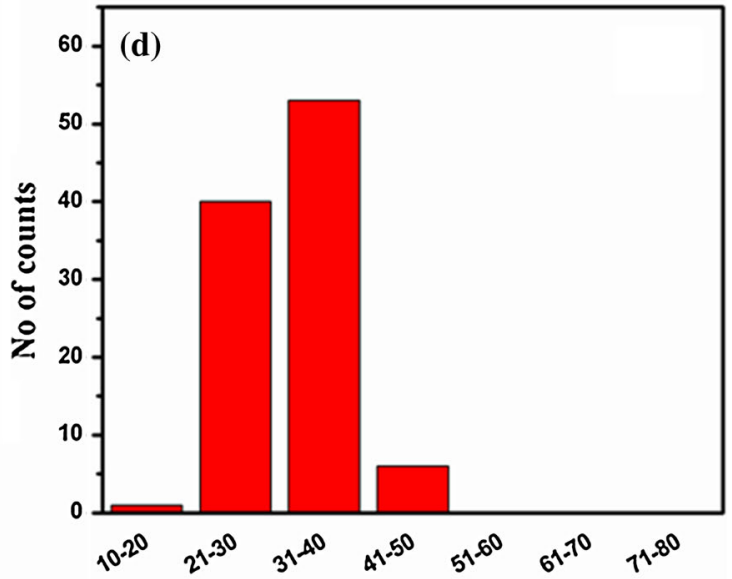

Fibre diameter $(\mathrm{nm})$

Fig. 2 Fiber diameter distribution of a PAN, b PAN $+0.5 \mathrm{wt} \% \mathrm{GO}, \mathbf{c}$ PAN $+1 \mathrm{wt} \% \mathrm{GO}$, d PAN $+1.5 \mathrm{wt} \% \mathrm{GO}$

ine the functional groups present in the electrospun nano fiber composite, as shown in Fig. 3a-d. The vibrational band appeared at 2,000-2,500 $\mathrm{cm}^{-1}$, which may be assigned to the presence of the nitrile groups in the composite nanofiber (Saeed et al. 2008; Nie et al. 2013). The band observed at $1,461 \mathrm{~cm}^{-1}$ is due to the $\mathrm{C}-\mathrm{H}$ bending vibration of the $\mathrm{CH}_{2}$ of polymeric chain. The $\mathrm{C}-\mathrm{O}-\mathrm{C}$ and $\mathrm{C}-\mathrm{O}$ stretching vibrations of the $\mathrm{GO}$ were observed at 1,280 and $1,700 \mathrm{~cm}^{-1}$, respectively. The peak appeared at $1,650 \mathrm{~cm}^{-1}$ is due to the vibrations of the skeletal structure of the aromatic ring domain in GO. This result shows that there was no chemical bonding between PAN and GO and intensity of the peak decreased, on increasing the GO in the nanofibrous composite, which may be due to the intermingling of GO with PAN yarn waste (Wang et al. 2012).

X-ray diffraction

Figure $4 \mathrm{a}$ shows the intensity peaks at $16.9^{\circ}(2 \theta)$ and $23.5^{\circ}(2 \theta)$ and their corresponding space $(d)$ of 5.24 and $3.81 \AA$, respectively, for the polyacrylonitrile nanofiber (Wu et al. 2008). Figure $4 \mathrm{~b}$ shows the major intensity peaks at $16.9^{\circ}$ and $25.12^{\circ}(2 \theta)$, and their corresponding space of 5.24 and $3.55 \AA$, respectively, for polyacrylonitrile yarn waste/0.5 wt\% GO composite nanofiber. Figure 4c shows the major intensity peaks at $12.1^{\circ}$, $16.9^{\circ}$, and $24.92^{\circ}$ and its corresponding space of 7.26 , 


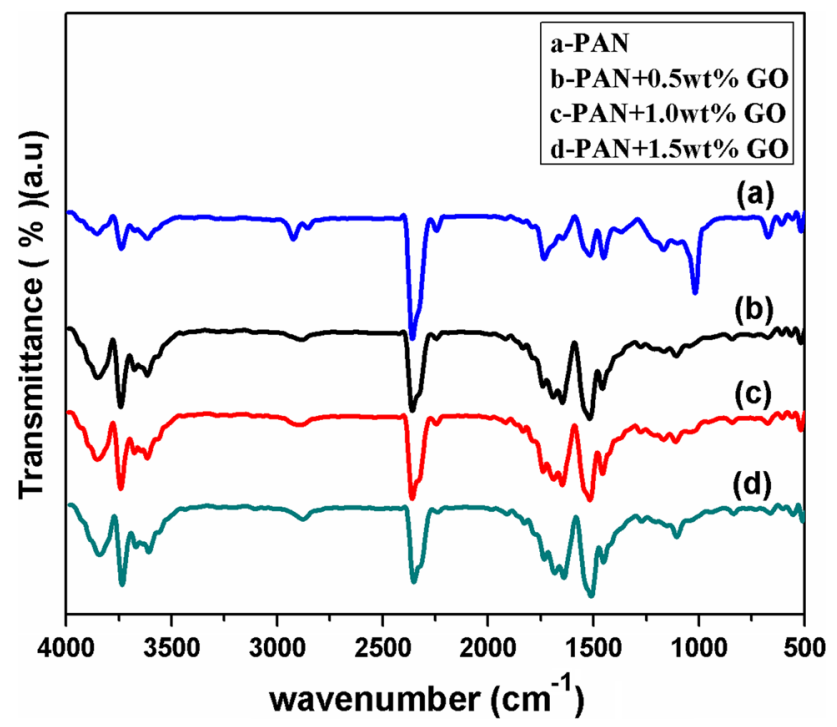

Fig. 3 FT-IR spectra of $a$ PAN, $b$ PAN + $0.5 \mathrm{wt} \%$ GO, $c$ PAN $+1 \mathrm{wt} \% \mathrm{GO}, d$ PAN $+1.5 \mathrm{wt} \% \mathrm{GO}$

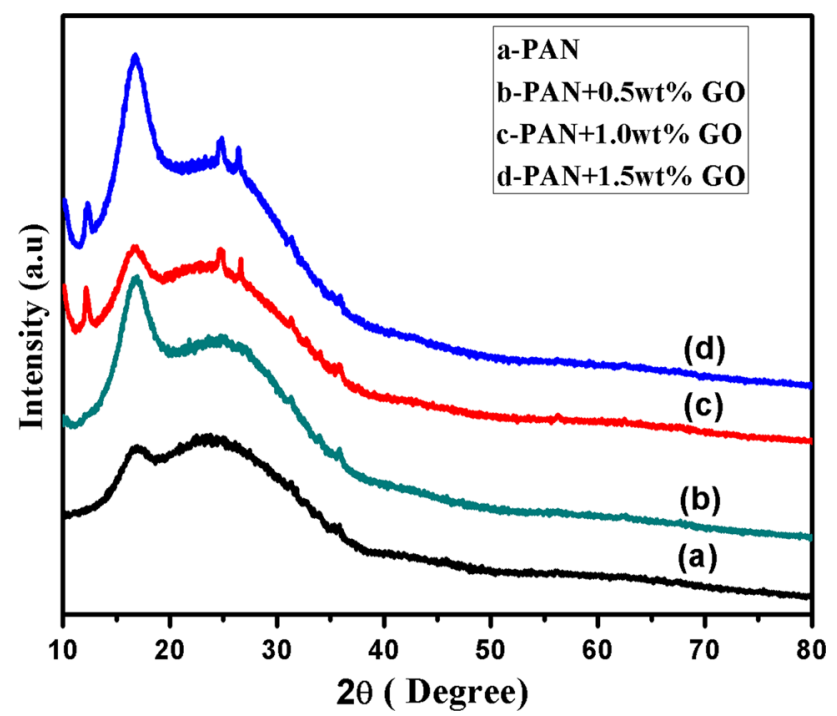

Fig. 4 XRD pattern of a PAN, b PAN $+0.5 \mathrm{wt} \%$ GO, $c$ PAN $+1 \mathrm{wt} \% \mathrm{GO}, d$ PAN $+1.5 \mathrm{wt} \% \mathrm{GO}$

5.24, and $3.58 \AA$, respectively, for polyacrylonitrile yarn waste/1.0 wt\% GO composite nanofiber. Figure $4 \mathrm{~b}-\mathrm{d}$ shows the major intensity peaks at $12.19^{\circ}, 16.9^{\circ}, 24.92^{\circ}$, and $26.48^{\circ}(2 \theta)$, and its corresponding space of 7.26 , 5.24, 3.58, and $3.25 \AA$, respectively, for polyacrylonitrile yarn waste/1.5 wt\% of GO composite nanofiber.

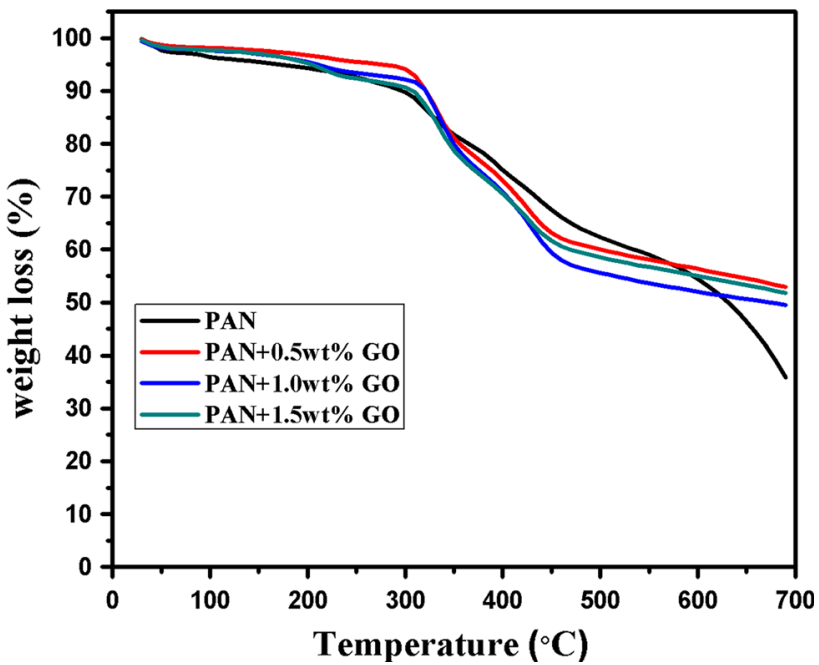

Fig. 5 Thermogravimetric analysis of $a$ PAN, $b$ PAN $+0.5 \mathrm{wt} \%$ $\mathrm{GO}, c \mathrm{PAN}+1 \mathrm{wt} \% \mathrm{GO}, d \mathrm{PAN}+1.5 \mathrm{wt} \% \mathrm{GO}$

The peak at $12.12^{\circ}$ corresponds to the interplanar spacing of GO. The peak at $16.88^{\circ}$ is associated with hexagonal structure of PAN and GO. The additional peaks at $24.56^{\circ}$ and $26.48^{\circ}$ present in Fig. $4 \mathrm{c}$, $\mathrm{d}$ indicate the disruption of crystalline structure of GO due to stabilization with PAN. It indicates that a significant portions of GO has been involved in linkage with PAN. In addition, intensity of the peak at $16.9^{\circ}$ upon addition of GO to PAN is a neat indication of formation of nanofibrous composite. Figure $4 b-d$ confirms the presence of GO dispersion in the PAN nanofiber. This peak is similar to that of the raw GO. The crystal sizes of the pristine PAN yarn waste, PAN yarn waste $/(0.5,1.0,1.5)$ wt $\%$ GO nanofibrous composites are 27.2, 33.49, 31.5, and $26 \AA$, respectively. The crystal size decreased with an increase in the wt\% of the GO, which may be due to the presence of GO in the PAN yarn waste nanofibrous composite, and also it may have affected the orientation of the fiber molecules in the PAN nanofiber. It proved that the amorphous content increased with increasing the wt $\%$ of GO.

Thermal stability

The thermal stability of the pure PAN yarn waste and PAN yarn waste $/(0.5,1.01 .5)$ wt $\%$ GO nanofibrous composites was studied using TGA. Figure $5 \mathrm{a}-\mathrm{d}$ shows 

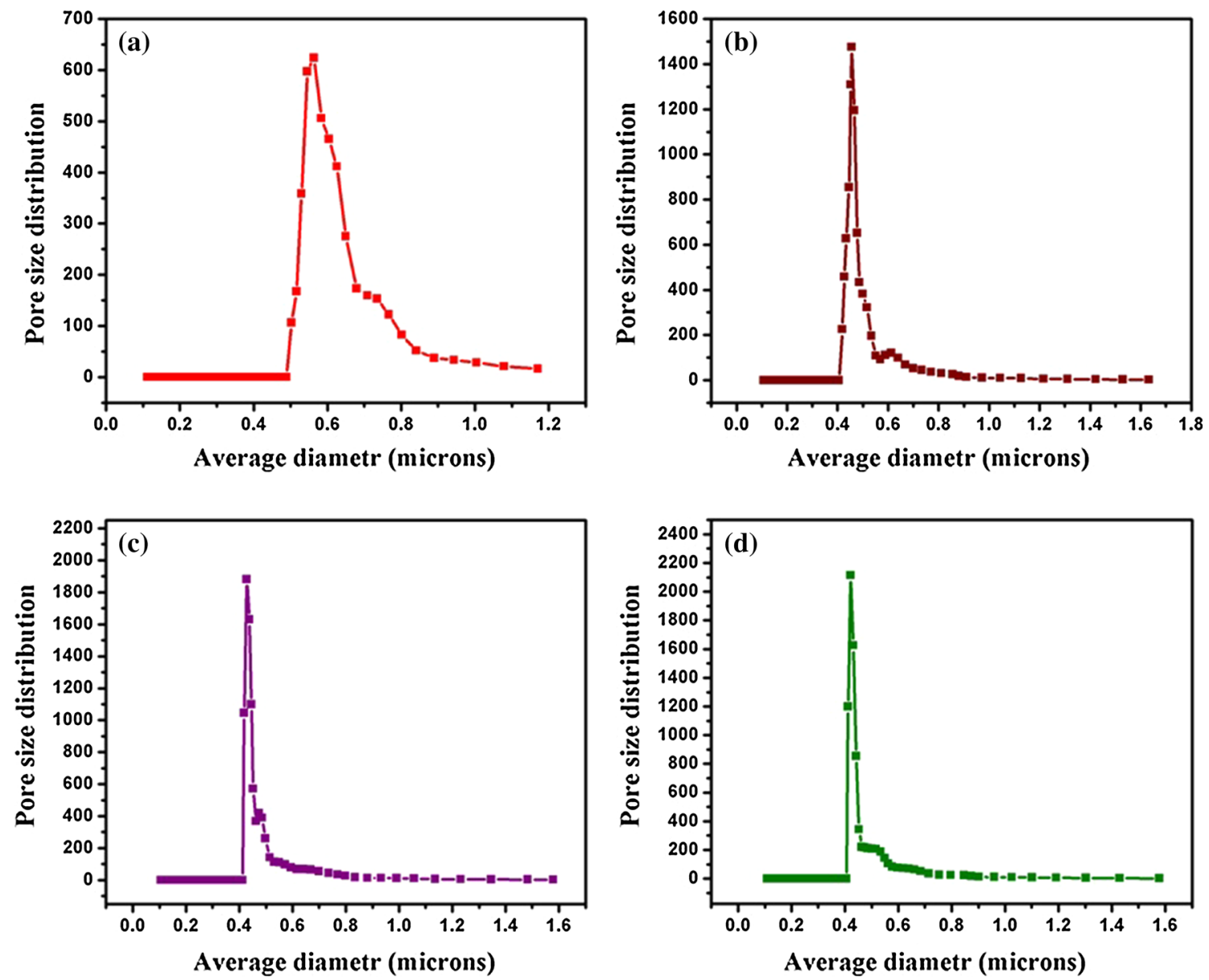

Fig. 6 Pore size distribution of a PAN, b PAN + 0.5 wt $\%$ GO, c PAN $+1 w t \%$ GO, d PAN + 1.5 wt $\%$ GO

the pristine PAN yarn waste and PAN yarn waste/(0.5, 1.0 1.5) wt $\%$ GO, respectively. Figure 5a shows the first stage weight loss at $100{ }^{\circ} \mathrm{C}$, due to the water evaporation in the mat. The second stage weight loss occurs at $280{ }^{\circ} \mathrm{C}$, due to the decomposition of the polymer chain (Khan and Baig 2013). Figure 5b shows the first weight loss at $100{ }^{\circ} \mathrm{C}$ for PAN yarn waste/0.5 wt\% GO composite mat, which may be attributed to water evaporation. The second weight loss occurs at $300{ }^{\circ} \mathrm{C}$. Figure $5 \mathrm{c}$ shows the first weight loss at $100{ }^{\circ} \mathrm{C}$ for the PAN yarn waste/1 wt\% GO composite, due to the water evaporation. The second stage weight loss takes place at $320{ }^{\circ} \mathrm{C}$. Figure $5 \mathrm{~d}$ shows the first stage weight loss at $100{ }^{\circ} \mathrm{C}$ for PAN yarn waste/1.5 wt $\%$ GO nanofibrous composite mat, which may be associated with water evaporation. The second stage weight loss starts at $310{ }^{\circ} \mathrm{C}$. The thermal stability is increased with increasing the GO content in the nanofibrous composite mat, when compared to pristine PAN yarn waste nanofibrous mat. However, the thermal stability of PAN yarn waste/1 wt \% GO is higher than that of the PAN yarn waste/1.5 wt\% GO nanofibrous mat, due to the presence of a higher amount of GO in the PAN yarn waste/ $1.5 \mathrm{wt} \% \mathrm{GO}$ fibrous mats. The GO may collapse the fibrous structure and also enhances the amorphous nature in the nanofibrous mat. C. Wang and B. Chen et al. found that the amorphous percentage increased with increasing the GO in the nanofibrous composite. The amorphous nature is one of the factors that increase the dye removal percentage.

Pore size distribution and porosity analysis

The pore size is decreased in the nanofibrous composite mat with increasing the GO in the polymer solution, as shown in Fig. 6. The percentage of porosity is increased 
with the addition of GO in the PAN polymer solution, which may be due to the better homogeneous dispersion of GO in the nanofibrous composite mat. The dye adsorption takes place not only via surface chelation on the outer surface of the nanofibrous mat but also on the internal surface by diffusion of the dye molecule into the pores of the nanofibers mat. A higher porosity with small pore size is also one of the factors that play a vital role for the diffusion of dye molecules to the inner surface sites of the fibrous composite mat.

\section{Effect of $\mathrm{pH}$ on adsorption}

The adsorption property of the PAN yarn waste/GO nanofibrous composite was studied at different $\mathrm{pH}$ range with $4 \mathrm{~h}$ reaction time. The dye adsorption rate was increased with the increase in $\mathrm{pH}$ range. The maximum adsorption rate was found to be higher at the optimum $\mathrm{pH}$ 8. With further increase in $\mathrm{pH}$, the dye adsorption rate was not significant. The $\mathrm{pH}$ may affect the surface properties of PAN yarn waste/GO nanofibrous composite mat. The basic $\mathrm{pH}$ may enhance the anionic site on the PAN yarn waste/GO nanofibrous composite. The PAN yarn waste $/ 1.5 \mathrm{wt} \%$ GO nanofibrous composite mat showed a higher adsorption capacity than the other fibrous composites at the same $\mathrm{pH}$ value, due to the presence of a higher number of absorptive sites in the PAN yarn waste/1.5 wt $\%$ GO nanofibrous composite, which may have enhanced the electrostatic interaction between the nanofibrous composite mat surface and the MB dye molecular structure. The effect of $\mathrm{pH}$ on the adsorption of MB onto the PAN yarn waste/GO nanofibrous composite mat is shown in Fig. 7. From Fig. 7, it can be observed that the adsorption capacity of the nanofibrous composite is minimum in an acidic $\mathrm{pH}$ and maximum in basic $\mathrm{pH}$.

\section{Effect of contact time}

The dye adsorption capacity of the PAN yarn waste/GO nanofibrous composite was carried out at different time intervals, at an optimum $\mathrm{pH} 8$ as shown in Fig. 8. In the first phase, the dye adsorption rate of the PAN yarn waste/ GO nanofibrous composite rapidly increased for the first $30 \mathrm{~min}$, due to the outer surface's active sites. In the second phase, the dye adsorption rate of the nanofibrous composites gradually increased for $420 \mathrm{~min}$, which is

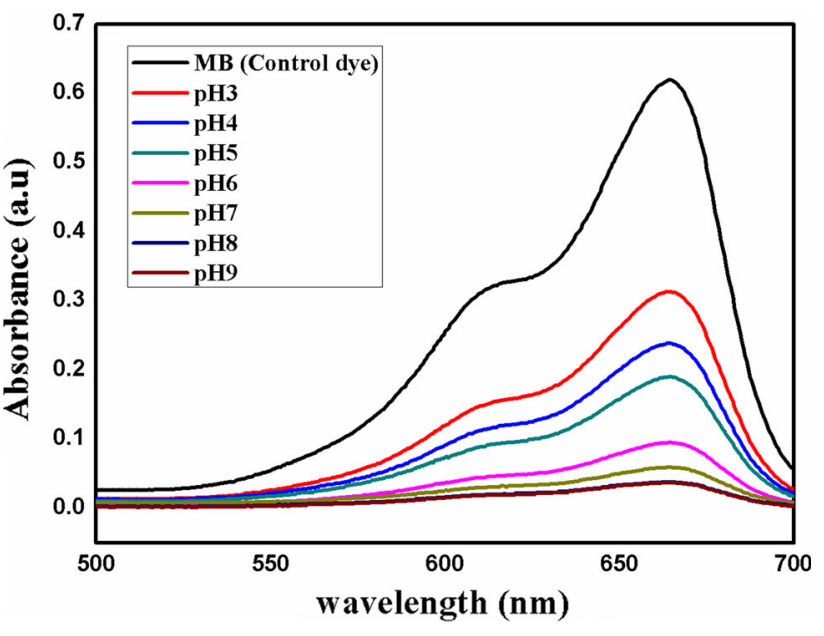

Fig. 7 Effect of pH on the removal methylene blue by PAN/GO nanofibrous composite mat

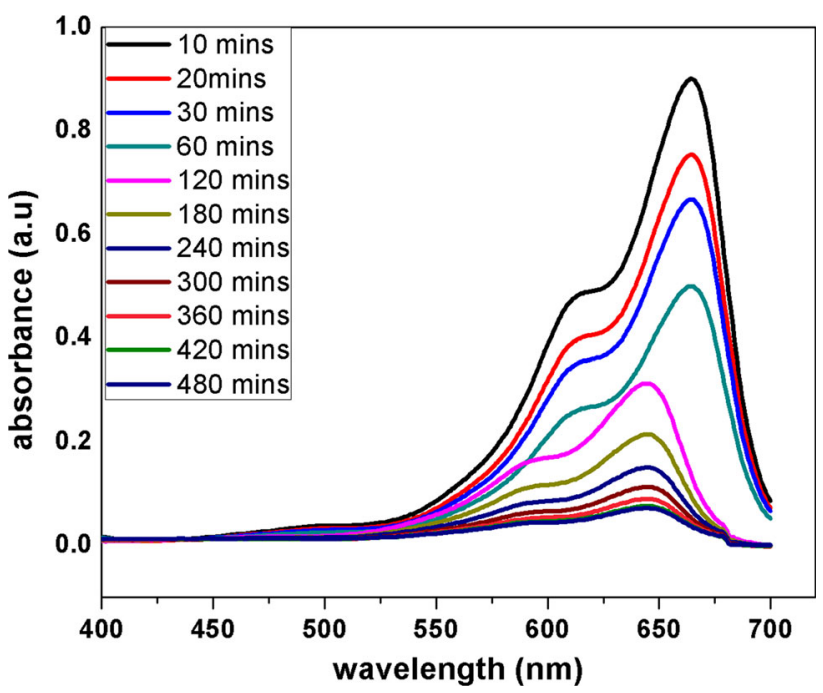

Fig. 8 Effect of contact time on the adsorption of methylene blue of PAN/GO nanofibrous composite

associated with the inner surface layer active sites of the nanofibrous composite. In the third phase, the dye adsorption rate reached the equilibrium point, which may be due to less accessible active sites in the nanofibrous composite. The rapid dye adsorption rate occurred for the first $30 \mathrm{~min}$ due to the presence of more active sites on the nanofibrous composite. After a certain period of contact time, the dye adsorption rate reached the equilibrium, due to the dye molecules being accumulated in the pores of the 
nanofibrous composite, which in turn decreased the dye adsorption.

\section{Effect of dye removal efficiency}

The percentage of dye removal increased on increasing the contact time. The maximum rapid dye removal occurred in the first $30 \mathrm{~min}$ as shown in Fig. 9, due to the presence of more surface active sites on the nanofibrous composite. The dye removal efficiency gradually increased up to a certain period of contact time; after that, it reached the

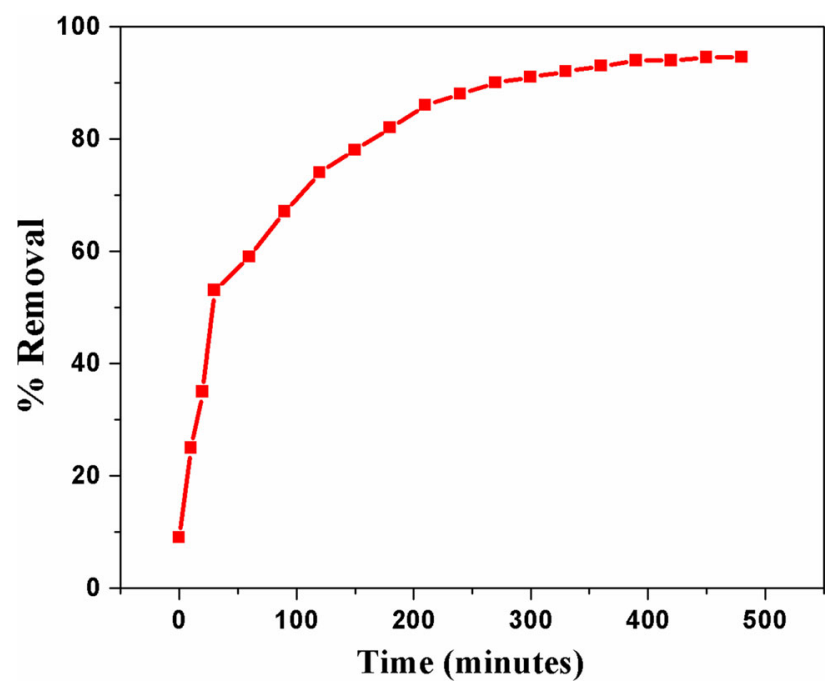

Fig. 9 Removal of dye efficiency with contact time

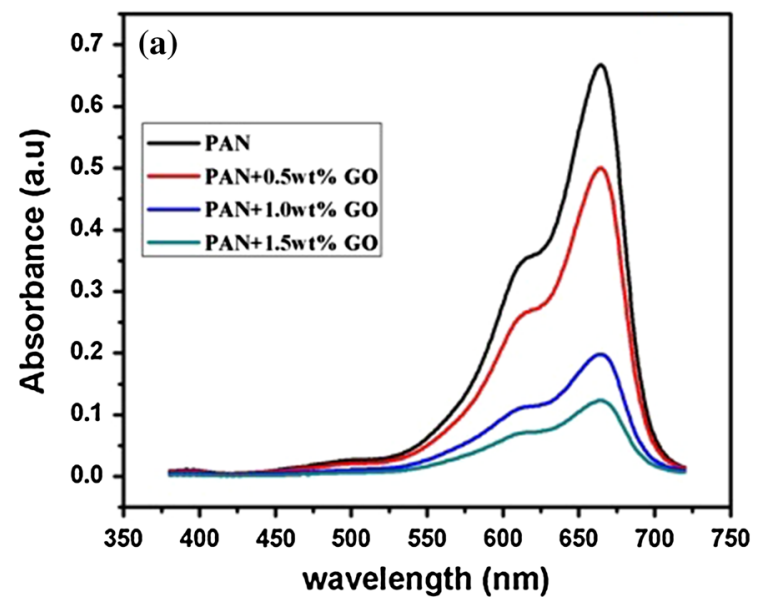

saturation point, which may be due to the presence of the inner surface active sites and the pores are blocked by dye molecules in medium.

Effect of graphene oxide dosage on dye removal efficiency

Figure 10b shows the dye removal efficiency of pristine PAN yarn waste, PAN yarn waste $/ 0.5 \mathrm{wt} \% \mathrm{GO}$, PAN yarn waste $/ 1.0 \mathrm{wt} \% \mathrm{GO}$, and PAN yarn waste $/ 1.5 \mathrm{wt} \%$ GO nanofibrous composites, for the same contact time of $240 \mathrm{~min}$ and optimum $\mathrm{pH}$ of 8 (Fig. 10a). The dye removal efficiency increased with the increase in the percentage of GO. From the result, it could be observed that the dye removal efficiency is lower in the pristine PAN yarn waste nanofibrous mat than in the PAN yarn waste/GO composite nanofibrous mat, due to the presence of GO in the PAN yarn waste/GO nanofibrous composites. The maximum dye removal is found to be higher in the PAN yarn waste/ $1.5 \mathrm{wt} \%$ GO nanofibrous composite than in the pristine PAN yarn waste, PAN $/ 0.5 \mathrm{wt} \% \mathrm{GO}$, and PAN yarn waste/ $1.0 \mathrm{wt} \% \mathrm{GO}$. The presence of higher amount of GO in the nanofibrous mat, in turn, increases the dye removal efficiency. Moreover, the addition of GO plays a vital role to reduce the pore size and diameter of the nanofibrous composite mat. The GO enhanced the amorphous content in the polymer nanofibrous composite, due to the good dispersion of GO in the nanofibrous composite, and also it provided a rough surface to the nanofibrous composite. The rough surface and amorphous structure are the factors that

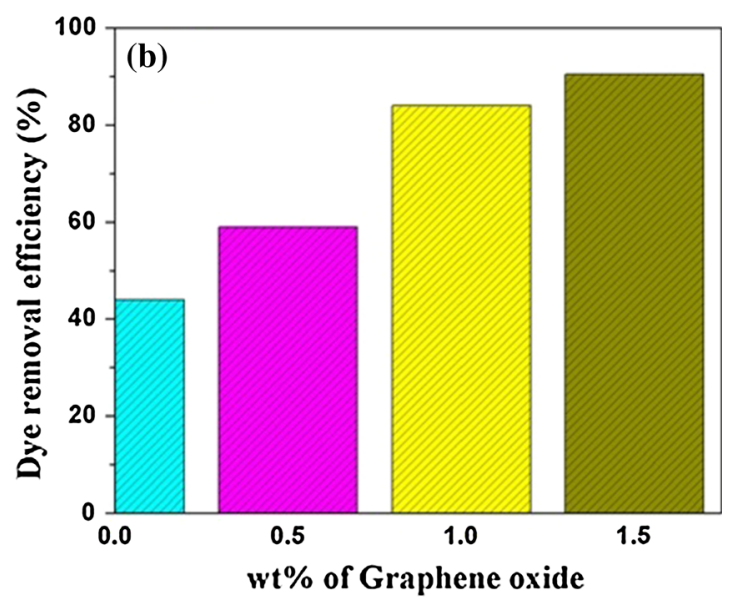

Fig. 10 Effect of graphene oxide dosage on a methylene blue adsorption performance and $\mathbf{b}$ dye removal efficiency 
improve the dye removal efficiency. The fiber diameter in the fibrous composite decreased with increasing the percentage of GO, thus reducing the pore size and increasing the porosity in the nanofibrous composite. The porosity and pore size are also factors that increase the dye removal efficiency in the PAN yarn waste/GO nanofibrous composite than in the pristine PAN yarn waste nanofibrous mat. The dye removal efficiency of the PAN $/ 1.5 \mathrm{wt} \%$ GO nanofibrous composite is twice that of the pure nanofibrous mat.

\section{Conclusion}

A nanofibrous composite was prepared from waste PAN yarn waste and GO. The diameter and pores size decreased with increasing the GO in the polymer solution. The crystal size decreased with increasing the GO in the polymer. The PAN yarn waste $1.5 \mathrm{wt} \%$ GO nanofibrous composite possessed lower thermal stability than the other nanofibrous composites. The dye removal efficiency of the PAN yarn waste/1.5 wt $\%$ GO composite was $90.5 \%$, at the optimized $\mathrm{pH}$ 8. The dye adsorption equilibrium was reached within $7 \mathrm{~h}$.

Acknowledgments The authors would like to convey grateful thanks to University Grants Commission, Delhi, India, for providing the funding facility to carry out this research work. UGC Sanction No. F.7-288/2009 (BSR), dated 27.12.2013. The authors are thankful to Dr. R. Jayavel and Mr. M. Shanmugam, Centre for Nanoscience and Technology, Anna University, Chennai, India, for providing an instrumental facility.

\section{References}

Auta M, Hameed BH (2011) Preparation of waste tea activated carbon using potassium acetate as an activating agent for adsorption of Acid Blue 25 dye. Chem Eng J 171:502-509

Ayad MM, Abo El-Nasr A (2010) Adsorption of cationic dye (methylene blue) from water using polyaniline nano-tubes base. J Phys Chem C 114:14377-14383

Baybars AF, Cengiz Q, Mustafa K (2012) Cationic dye (methylene blue) removal from aqueous solution by montmorillonite. Bull Korean Chem Soc 33:3184-3190

Bradder P, Ling SK, Wang SB, Liu SM (2011) Dye adsorption on layered graphite oxide. J Chem Eng Data 56:138-141

Buchkoa CJ, Chena LC, Shena Y, Martin DC (1999) Processing and microstructural characterization of porous biocompatible protein polymer thin films. Polymer 40:7397-7407

Christian Kemp K, Seema H, Saleh M, Le NH, Mahesh K, Chandraa V, Kim K (2013) Environmental applications using graphene composites: water remediation and gas adsorption. Nanoscale 5:3149-3171

Dubey SP, Gopal K, Bersillon JL (2009) Utility of adsorbents in the purification of drinking water: a review of characterization, efficiency and safety evaluation of various adsorbents. J Environ Biol 30:327-332

Gomes AC, Goncalves IC, De Pinho MN (2005) The role of adsorption on nanofiltration of azo dyes. J Membr Sci 255:157-165

Gupta VK, Suhas (2009) Application of low-cost adsorbents for dye removal-a review. J Environ Manag 90:2313-2342

Hasanzadeh M, Moghadam BH (2013) Electrospun nanofibrous membranes as potential adsorbents for textile dye removal. J Chem Health Risks 3:15-26

Huang ZM, Zhang YZ, Kotaki M, Ramakrishna S (2003) A review on polymer nanofibers by electrospinning and their applications in nanocomposites. Compos Sci Technol 63:2223-2253

Khan AA, Baig U (2013) Preparation, characterization, and properties of polyacrylonitrile-silica gel anion exchange composite fibers. Polym Eng Sci 53:2027-2033

Linjun S, Guiying X, Weixi L, Huijun Y, Mingxi Q, Xian-Man Z, Chenze Q (2013) Photodegradation of azo-dyes in aqueous solution by polyacrylonitrile nanofiber mat-supported metalloporphyrins. Polym Int 62:289-294

Liu T, Li Y, Du Q, Sun J, Jiao Y, Yang G, Wang Z, Xia Y, Zhang W, Wang K, Zhu H, Wu D (2012) Adsorption of methylene blue from aqueous solution by graphene. Colloid Surf B 90:197-203

Nassar MM, El-Geundi MS, Al-Wahbi AA (2012) Equilibrium modeling and thermodynamic parameters for adsorption of cationic dyes onto Yemen natural clay. Desalin Water Treat 44:340-349

Nie G, Li Z, Lu X, Lei J, Zhang C, Wang C (2013) Fabrication of polyacrylonitrile/CuS composite nanofibers and their recycled application in catalysis for dye degradation. Appl Surf Sci 284:595-600

Ohkawa K, Cha D, Kim H, Nishida A, Yamamoto H (2004) Electrospinning of chitosan. Macromol Rapid Commun 25:1600-1605

Pang XY, Gong F (2008) Study on the adsorption kinetics of acid red 3B on expanded graphite. J Chem 5:802-809

Qingqing W, Yuanzhi D, Quan F, Fenglin H, Keyu L, Jingyan L, Qufu W (2013) Nanostructures and surface nanomechanical properties of polyacrylonitrile/graphene oxide composite nanofibers by electrospinning. J Appl Polym Sci 128:1152-1157

Ramesha GK, Vijaya Kumara A, Muralidhara HB, Sampath S (2011) Graphene and graphene oxide as effective adsorbents toward anionic and cationic dyes. J Colloid Interf Sci 361:270-277

Saeed K, Haider S, Oh TJ, Park SY (2008) Preparation of amidoxime modified polyacrylonitrile (PAN-oxime) nanofibers and their applications to metal ions adsorption. J Membr Sci 322:400-405

Sivakumar P, Palanisamy PN (2009) Adsorption studies of basic red 29 by a nonconventional activated carbon prepared from Euphorbia antiquorum $L$. Int J Chem Tech Res 1:502-510

Teo WE, Ramakrishna S (2006) A review on electrospinning design andnanofiber assemblies. Nanotechnology 17:89-106

Wang Q, Du Y, Feng Q, Huang F, Lu K, Liu J, Weil Q (2012) Nanostructures and surface nanomechanical properties of polyacrylonitrile/graphene oxide composite nanofibers by electrospinning. J Appl Polym Sci 128:1152-1157 
Wong YC, Szeto YS, Cheung WH, McKay G (2003) Equilibrium studies for acid dye adsorption onto chitosan. Langmuir 19:7888-7894

Wu S, Feng Z, Xiaoxiao H, Xiaoping Y (2008) Stretching-induced orientation for improving the mechanical properties of electrospun polyacrylonitrile nanofiber sheet. Adv Mater Res 47:1169-1172

Zhao S, Guo B, Han G, Tian Y (2008) Metallization of electrospun polyacrylonitrile fibers by gold. Mater Lett 62:3751-3753 